\title{
Amelanotic melanoma of the skin - detailed review of the problem
}

\section{Strahil Strashilov ${ }^{1}$, Veselin Kirov ${ }^{2}$, Angel Yordanov ${ }^{3}$, Yoana Simeonova ${ }^{4}$ and Miroslava Mihailova ${ }^{5}$}

1. Department of Plastic Restorative, Reconstructive and Aesthetic Surgery, Medical University Pleven, Bulgaria

2. Department of Oncodermatology, Medical University Pleven, Bulgaria

3. Department of Gynecologic Oncology, Medical University Pleven, Bulgaria

4. Department of Pharmaceutical Sciences and Social Pharmacy, Medical University Pleven, Bulgaria

5. Department of Gastroenterology, Medical University Pleven, Bulgaria

\section{RESEARCH}

Please cite this paper as: Strashilov S, Kirov V, Yordanov A, Simeonova $\mathrm{Y}$, Mihailova M. Amelanotic melanoma of the skin - detailed review of the problem. AMJ 2018;11(12):542-548.

https://doi.org/10.21767/AMJ.2018.3511

\section{Corresponding Author:}

Angel Danchev Yordanov

Clinic of Gynecologic Oncology, University Hospital "Dr. Georgi Stranski"-Pleven, Georgi Kochev 8A, Bulgaria Email: angel.jordanov@gmail.com

\section{ABSTRACT}

\section{Background}

Malignant melanoma (MM) of the skin accounts for about one per cent of all malignancies in humans. Amelanotic melanoma is a rare tumour, diagnosed in eight per cent of all melanomas.

\section{Aims}

The study aimed to analyse our clinical experience with amelanotic MM of the skin and the statistical data from a retrospective five year analysis of pigmented and amelanotic types of skin melanoma. Furthermore, we compare our results to those from other teams' studies. To reach the corresponding in-depth conclusions.

\section{Methods}

The study included 151 patients with malignant melanoma of the skin, diagnosed and treated at Dr. Georgi Stranski University in Pleven, Bulgaria, between 2012 and 2016. All the patients signed informed consent forms.

\section{Results}

Of the 151 patients we studied, 14 (9.3 per cent) were diagnosed with amelanotic melanoma. The average Breslow thickness in patients with amelanotic MM was $4.2 \mathrm{~mm}$, while in pigmented $\mathrm{MM}$ patients it $2.1 \mathrm{~mm}$. Local recurrence rates (35.7 per cent) were higher in patients with amelanotic melanoma. Distant metastases were found in 39 of all tested patients with melanoma. Of the 14 patients with amelanotic MM, eight had such metastases.

\section{Conclusion}

Amelanotic melanoma was diagnosed too late. Local recurrences were six times as many as the ones diagnosed in pigment melanoma. Distant metastases were twice as many, and mortality rates were three times higher.

\section{Key Words}

Amelanotic melanoma, malignant melanoma, pigment melanoma

\section{What this study adds:}

\section{What is known about this subject?}

Amelanotic melanoma is a rare tumour, diagnosed in eight per cent of all melanomas and its progression is more malignant as compared to that of pigmented MM.

\section{What new information is offered in this study?}

Amelanotic melanoma has more often local recurrences, distant metastases and the mortality rate is three times as high as pigmented melanoma.

3. What are the implications for research, policy, or practice?

Amelanotic melanoma has to be treated more aggressively and monitored more actively than pigmented melanoma.

\section{Background}

Malignant melanoma ( $\mathrm{MM}$ ) of the skin accounts for around 
one per cent of all malignancies in humans. Amelanotic skin MM lacks melanin or, when present, it is in minimal amounts. MM is a rare tumour found in approximately eight per cent of all diagnosed melanomas. The diagnostic procedures employed include local dermatoscopy and biopsy of the skin lesion. The final diagnosis is confirmed after standard histological and immunohistochemical testing. ${ }^{1-6}$ Macroscopically, the tumour presents as a red or pink-pigmented lesion. ${ }^{7,8}$ Histologically, the subtypes of amelanotic melanoma are identical with the pigment type of $\mathrm{MM}$ and include nodular superficial spreading of lentigo maligna and acral lentiginosis. ${ }^{1,9}$ The diagnosis is difficult to make and is usually late, due to the lack of typical clinical presentation. The differential diagnosis includes a variety of skin diseases, such as eczema, psoriasis, rosacea, actinic and seborrheic keratosis, granuloma annulare, discoid lupus erythematosus, Bowen's disease, basal-cell carcinoma. ${ }^{10}$ Amelanotic $\mathrm{MM}$ is more aggressive than pigment $\mathrm{MM}$. Local recurrences, distant metastases are more common, and the mortality rate is higher. ${ }^{11}$

\section{Method}

The study included 151 with MM of the skin, who were diagnosed and treated at Dr. Georgi Stranski university hospital in Pleven, Bulgaria during the period 2012-2016. The average age of patients with pigmented melanoma was 66 years, age range 17-91 years. The average age of those with amelanotic melanoma was 65 , varying between 31 and 81 years. Of all the patients studied, 14 (9.3 per cent) were diagnosed with amelanotic skin MM. All the patients signed informed consent forms. The study was reviewed and approved by the ethics committee for clinical research at the Medical University-Pleven.

Evaluation was based on the following criteria: gender, age, Breslow thickness, Clark level of invasion, sentinel biopsy of the regional lymph pool, presence of a positive sentinel lymph node, performed lymph dissection, presence of distant metastases, presence of local recurrences, number of months till recurrence, mortality rates, and survival in months. The statistical analysis is retrospective. The methods employed were as follows: summary of the processed data, cross tabulation, and chi-square test. The survivability was analysed by the Kaplan-Meier function for survivability. The statistical analysis was made with IBM SPSS Statistics 23.

\section{Results}

Of the 151 patients with MM, 14 (9.3 per cent) were diagnosed with its amelanotic type (Table 1 ).
Table 1: Distribution of patients diagnosed with pigmented and amelanotic melanoma

\begin{tabular}{|l|l|l|l|}
\hline Indicator & $\begin{array}{l}\text { Pigmented } \\
\text { MM }\end{array}$ & Amelanotic MM & Total \\
\hline Number & 137 & 14 & 151 \\
\hline Percent & $90.70 \%$ & $9.30 \%$ & $100 \%$ \\
\hline
\end{tabular}

Pigmented melanoma was slightly prevalent in the male patients: 51.8 per cent vs. 48.2 per cent in the females. However, the number of males with amelanotic MM was equal to that of the females: seven cases for each group $(p=0.896)$ (Table 2).

Pigmented melanoma was generally localized in the back area (33 patients), on the lower extremity (31 patients), in the head area (29 patients) and the upper extremity (19 patients). Amelanotic melanoma was located mostly in the lower extremity (four cases), in the head area (three cases), back area (three cases). It rarely affected the neck area (one case), the chest (one case), lumbar area (one case) and the upper extremity (one case) (Table 3 ).

The mean thickness of Breslow melanoma was more significant in patients with an amelanotic MM $(4.2 \mathrm{~mm})$ than those with a pigment $(2.1 \mathrm{~mm})$, and the difference between the groups was significant $(U=0.584 ; p=0.016)$ (Table 4 and Figure 1).

Figure 1: Distribution of melanoma by Breslow thickness

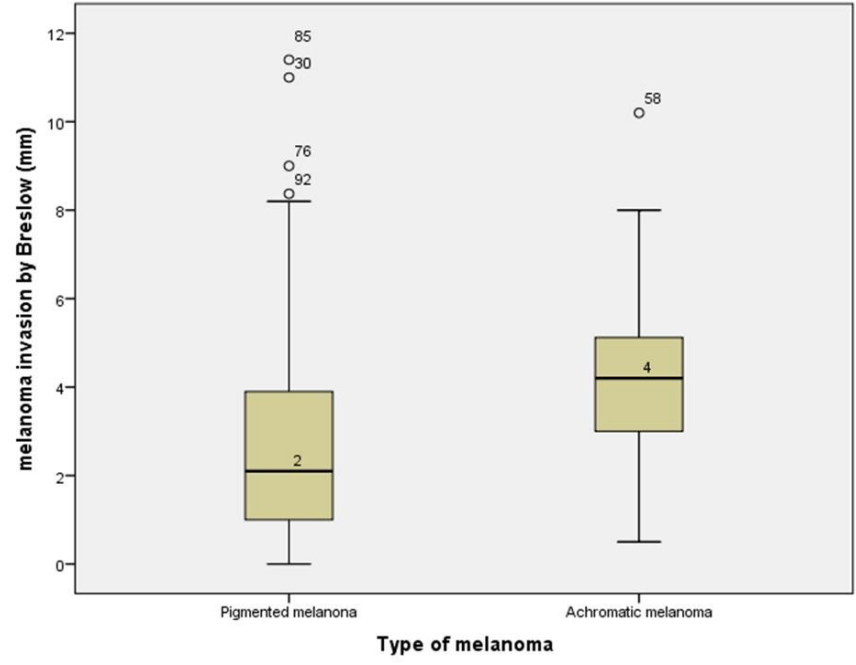

Evaluation of invasion after Clark revealed invasion into the reticular dermis in the majority of the patients: in 58 patients with pigmented $\mathrm{MM}$, and in eight patients with amelanotic MM. Invasion into the papillary or reticular 
dermis was found in 41 patients with pigmented MM, and in three with amelanotic MM (Table 5).

According to the TNM system for classification of malignant tumours, approximately 25 per cent of the patients had the IV stage of the disease: 32 with pigmented melanoma, six with amelanotic (Table 6).

Sentinel lymph node biopsy (SLNB) was performed relatively more often in patients with pigmented melanoma (Table 7).

Table 7: Sentinel lymph biopsy performed in cases of pigmented and amelanotic MM

\begin{tabular}{|l|l|l|l|}
\hline SLNB & $\begin{array}{l}\text { Pigmented } \\
\text { melanoma }\end{array}$ & $\begin{array}{l}\text { Amelanotic } \\
\text { melanoma }\end{array}$ & Total $(\mathbf{n})$ \\
\hline $\begin{array}{l}\text { Not } \\
\text { performed }\end{array}$ & $81(59 \%)$ & $12(85.7 \%)$ & 93 \\
\hline Performed & $56(41 \%)$ & $2(14.3 \%)$ & 58 \\
\hline Total $(n, \%)$ & $137(100 \%)$ & $14(100 \%)$ & 151 \\
\hline
\end{tabular}

* Sentinel lymph node biopsy

In 34 of the patients with pigmented melanoma and seven with amelanotic melanoma, the lymph dissection was performed in cases of pathologically confirmed metastases in lymph nodes (Table 8).

The frequency of local recurrence was six times higher in patients with amelanotic melanoma (35.7 per cent) compared to those with pigmented MM (5.8 per cent), and the differences in the groups are statistically significant $(x 2=14.408 ; p=0.001)$ (Figure 2 ).

\section{Figure 2: Distribution of melanoma by stages of disease}

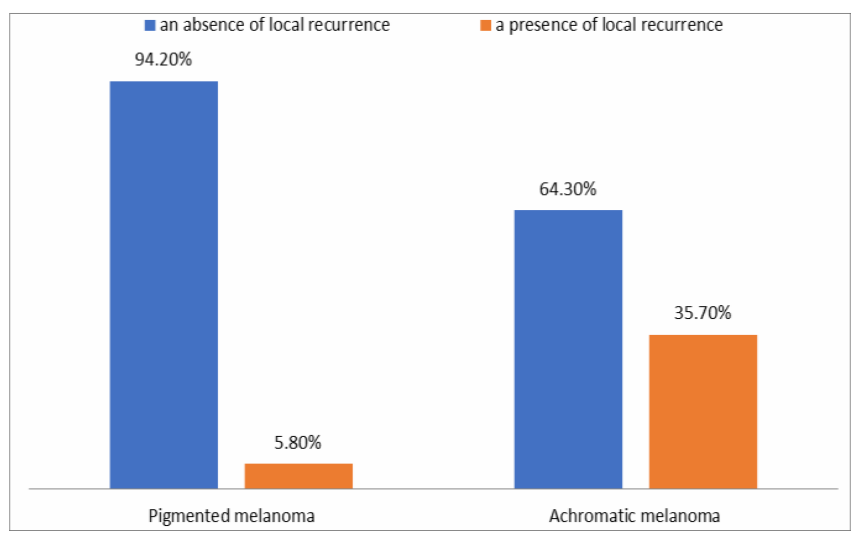

The average time for local recurrence was 11 months for patients with pigmented and 12 months for patients with amelanotic melanoma, and the differences in the groups were not significant $(U=15.000 ; p=0.459)$.
Distant metastases were found in 39 of all tested patients with melanoma, and they were more than twice as many in patients with amelanotic melanoma (57.1 per cent) as compared to patients with pigmented melanoma (22.6 per cent) with $p=0.005$ (Figure 3).

Figure 3: Distribution of melanoma by distant metastases

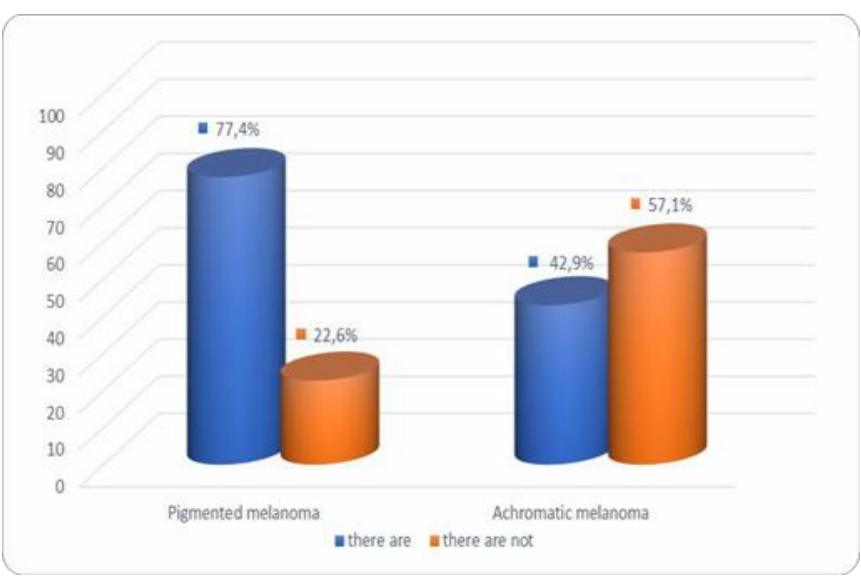

In 21 of the patients with pigmented melanoma and five of those with amelanotic melanoma the distant metastases affected one organ, and in eight of the patients with pigmented melanoma two organs were affected (Table 9).

Table 9: Organs affected in patients with pigmented MM and amelanotic MM

\begin{tabular}{|l|l|l|l|l|}
\hline $\begin{array}{l}\text { Distant metastasis } \\
\text { melanoma }\end{array}$ & $\begin{array}{l}\mathbf{1} \\
\text { organ }\end{array}$ & $\begin{array}{l}\mathbf{2} \\
\text { organs }\end{array}$ & $\begin{array}{l}\mathbf{3} \\
\text { organs }\end{array}$ & Total \\
\hline $\begin{array}{l}\text { Pigmented } \\
\text { melanoma }\end{array}$ & 21 & 8 & 2 & 31 \\
\hline $\begin{array}{l}\text { Amelanotic } \\
\text { melanoma }\end{array}$ & 5 & 1 & 2 & 8 \\
\hline Total & 26 & 9 & 4 & 39 \\
\hline
\end{tabular}

Distant metastases were found mostly in the skin: in 18 patients with pigmented $\mathrm{MM}$ and in four patients with amelanotic MM. In two of the patients with amelanotic $\mathrm{MM}$, distant metastases were found in the small intestine (1 patient) and the lungs ( 1 patient), and in two patients with amelanotic MM, the tumour metastasized in the skin, lungs, and liver.

The mortality was three times higher in the patients with amelanotic melanoma (71.4 per cent), as compared to the mortality of patients with pigmented melanoma (26.3 per cent), and the differences in the two groups were significant $(\chi 2=12.224 ; p=0.001)$ (Figure 4). 
Figure 4: Distribution of melanoma by mortality

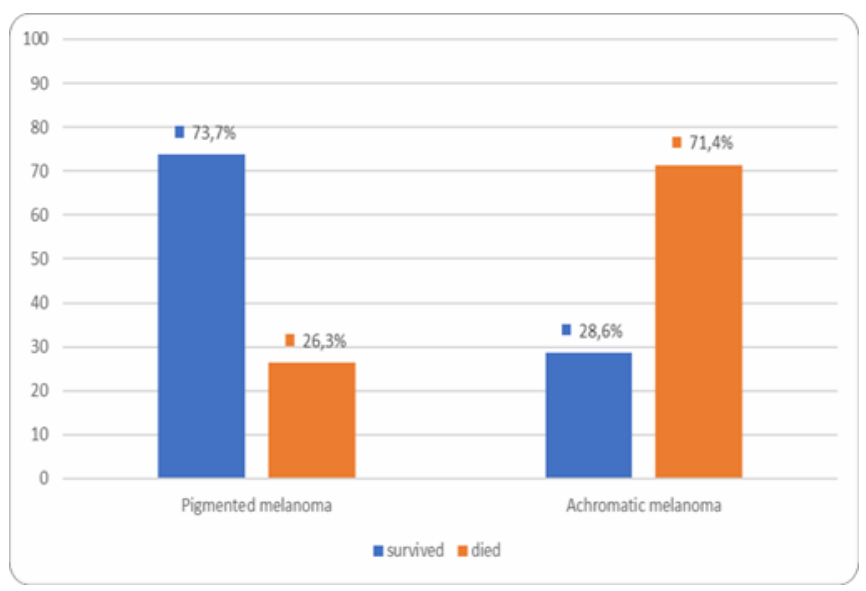

The median survival was higher in the patients with pigmented $\mathrm{MM}$ ( $\mathrm{Mdn}=28$ months, $4 \div 72$ ) as compared to the patients with amelanotic $\mathrm{MM}(\mathrm{Mdn}=24.5$ months, $10 \div 120)$ with $\mathrm{p}=0.653$ ).

\section{Discussion}

In our study, amelanotic MM accounted for 9.3 per cent of all the MM cases. This ratio was a little higher than the eight per cent incidence reported in the literature. ${ }^{2,4,6,11}$ Our data showed that amelanotic melanoma affected the men and women equally, while the pigmented $\mathrm{MM}$ affected more males than females. Similar studies by other teams have reported contradicting data. Some have found a higher frequency of amelanotic melanoma in men ${ }^{11-13}$ and others in women. ${ }^{1,2}$ An equal number of affected males and females was reported in one study. ${ }^{14}$

Both types of melanomas in our sample affected older patients. This finding corresponded to results from similar studies. $^{11,12}$

The most common localization MM was in the lower extremities (28.6 per cent of the cases). For pigmented MM, the back localization accounted for 24.1 per cent. Some authors have reported a higher incidence of involvement of the back and the chest for both types of melanoma. ${ }^{11}$

The average Breslow thickness we found was significantly higher $(U=0.584, p=0.01)$ in amelanotic $M M(4.2 \mathrm{~mm})$ as compared with the thickness in pigmented $\mathrm{MM}(2.1 \mathrm{~mm})$. This finding coincides with the results established by other authors. ${ }^{5,11,12,15}$ However, our results for average thickness from investigating both pigmented and amelanotic MM were about twice as high. According to our data, the deep invasion in both types of melanoma was mostly found in the reticular dermis, which corresponds to Clark IV.
Unfortunately, our results showed, that the largest percentage of patients with both types of melanoma was in the IV clinical stage, while patients included in other studies were in I and II stages. ${ }^{11}$

Sentinel lymph node biopsy was performed in 41 per cent of patients with pigmented MM, and in 14.3 per cent of those with amelanotic MM. Approximately one-third of pigmented MM patients and half of those with amelanotic $\mathrm{MM}$, underwent regional lymph node dissection after a lymph node had been proved clinically positive. This implies a more malignant progression of amelanotic MM.

The rate of local recurrences in the cases of amelanotic MM was significantly higher - about six times, $(\chi 2=14.408$; $p=0.001)$ as compared to those with pigmented melanoma. The time before a relapse in cases of amelanotic MM and pigmented MM was 12 and 11 months, respectively. Distant metastases in the amelanotic type are also significantly ( $p=0.005$ ) higher (about two times), as compared with the pigmented type. In amelanotic MM, distant metastases were detected in one organ, usually the skin. The data on the more common local recurrences and distant metastases in the cases of amelanotic melanoma we found explain the worse prognosis in amelanotic MM. Our data on recurrences and distant metastases coincide with the data reported by other researchers. ${ }^{11}$

Lethality in cases with amelanotic MM was significantly higher $(\chi 2=12.224 ; p=0.001)$ than in those of patients with pigmented $\mathrm{MM}$, and the median survival was 24.5 and 28 months, respectively. Our results coincide with the data from other similar studies. ${ }^{2,11}$

\section{Conclusion}

The diagnosis of amelanotic melanoma was made later than that of pigmented melanoma when the thickness of the tumour was significantly bigger. The progression of the amelanotic $\mathrm{MM}$ is more malignant as compared to that of pigmented MM. In the amelanotic type, local recurrences are 6 times more common, and distant metastases were twice more frequent. The mortality rate in patients with amelanotic melanoma was three times as high, as compared to the patient with pigmented MM, and the median survival was lower.

\section{References}

1. McClain SE, Mayo KB, Shada AL, et al. Amelanotic melanomas presenting as red skin lesions: a diagnostic challenge with potentially lethal consequences. Int J Dermatol. 2012;51(4):420-426. 
2. Huvos AG, Shah JP, Goldsmith HS. A clinicopathologic study of amelanotic melanoma. Surg Gynecol Obstet. 1972;135(6):917-920.

3. Ariel IM. Amelanotic melanomas: an analysis of 77 patients. Curr Surg. 1981;38(3):151-155.

4. Barnhill RL, Fine JA, Roush GC, et al. Predicting five-year outcome for patients with cutaneous melanoma in a population-based study. Cancer. 1996;78(3):427-432.

5. Balch CM, Murad TM, Soong SJ, et al. A multifactorial analysis of melanoma: prognostic histopathological features comparing Clark's and Breslow's staging methods. Ann Surg. 1978;188(6):732-742.

6. Søndergaard K, Schou G. Survival with primary cutaneous malignant melanoma, evaluated from 2012 cases: a multivariate regression analysis. Virchows Arch A Pathol Anat Histopathol. 1985;406(2):179-195.

7. Adler MJ, White CRJ. Amelanotic malignant melanoma. Semin Cutan Med Surg. 1997;16:122-130.

8. Bono A, Maurichi A, Moglia D, et al. Clinical and dermatoscopic diagnosis of early amelanotic melanoma. Melanoma Res. 2001;11:491-494.

9. Massi D, Pinzani $P$, Simi L, et al. BRAF and KIT somatic mutations are present in amelanotic melanoma. Melanoma Res. 2013;23(5):414-9.

10. Rahbari $\mathrm{H}$, Nabai $\mathrm{H}$, Mehregan $\mathrm{AH}$, et al. Amelanotic lentigo maligna melanoma. Cancer. 1996;77:2052-2057.

11. Thomas NE, Kricker A, Waxweiler WT, et al. Comparison of clinicopathologic features and survival of histopathologically amelanotic and pigmented melanomas: a population-based study. JAMA Dermatol. 2014;150(12):1306-1314.

12. Moreau JF, Weissfeld JL, Ferris LK. Characteristics and survival of patients with invasive amelanotic melanoma in the USA. Melanoma Res. 2013;23(5):408-13.

13. Cheung WL, Patel RR, Leonard A, et al. Amelanotic melanoma: a detailed morphologic analysis with clinicopathologic correlation of 75 cases. J Cutan Pathol. 2012;39(1):33-39.

14. Giuliano AE, Cochran AJ, Morton DL. Melanoma from unknown primary site and amelanotic melanoma. Semin Oncol. 1982;9(4):442-447.

15. Gualandri L, Betti R, Crosti C. Clinical features of 36 cases of amelanotic melanomas and considerations about the relationship between histologic subtypes and diagnostic delay. J Eur Acad Dermatol Venereol. 2009;23(3):283287.

\section{PEER REVIEW}

Not commissioned. Externally peer reviewed.

\section{CONFLICTS OF INTEREST}

The authors declare that they have no competing interests.

\section{FUNDING}

This publication is supported by Project N BG05M2OP0012.009-0031-C01

\section{ETHICS COMMITTEE APPROVAL}

N/A 
Table 2: Distribution of patients with MM by gender

\begin{tabular}{|l|l|l|l|l|}
\hline $\begin{array}{l}\text { Gender } \\
\text { distribution }\end{array}$ & Indicator & $\begin{array}{l}\text { Pigmented } \\
\text { MM }\end{array}$ & $\begin{array}{l}\text { Amelanotic } \\
\text { MM }\end{array}$ & Total \\
\hline \multirow{4}{*}{ Men } & Number & 71 & 7 & 78 \\
\cline { 2 - 5 } & Percentage of total & $91 \%$ & $9 \%$ & $100 \%$ \\
\cline { 2 - 5 } & Percentage in the groups & $51.8 \%$ & $50 \%$ & \\
\hline \multirow{3}{*}{ Women } & Number & 66 & 7 & 73 \\
\cline { 2 - 5 } & Percentage of total & $90.4 \%$ & $9.6 \%$ & $100 \%$ \\
\cline { 2 - 5 } & Percentage in the groups & $48.2 \%$ & $50 \%$ & \\
\hline
\end{tabular}

Table 3: Localisation of pigmented MM and amelanotic MM

\begin{tabular}{|l|l|l|l|l|}
\hline \multirow{2}{*}{ Localization } & Indicator & $\begin{array}{l}\text { Pigmented } \\
\text { MM }\end{array}$ & Amelanotic MM & Total \\
\hline \multirow{3}{*}{ Head } & Number & 29 & 3 & 32 \\
\cline { 2 - 5 } & Percentage & $21.20 \%$ & $21.40 \%$ & $21.20 \%$ \\
\hline \multirow{3}{*}{ Check } & Number & 0 & 1 & 1 \\
\cline { 2 - 5 } & Percentage & $0.00 \%$ & $7.10 \%$ & $0.70 \%$ \\
\hline \multirow{3}{*}{ Abdomen } & Number & 10 & 1 & 11 \\
\cline { 2 - 5 } & Percentage & $7.30 \%$ & $7.10 \%$ & $7.30 \%$ \\
\hline \multirow{3}{*}{ Back } & Number & 10 & 0 & 10 \\
\cline { 2 - 5 } & Percentage & $7.30 \%$ & $0.00 \%$ & $6.60 \%$ \\
\hline \multirow{2}{*}{ Lumbar area } & Number & 33 & 3 & 36 \\
\cline { 2 - 5 } & Percentage & $24.10 \%$ & $21.40 \%$ & $23.80 \%$ \\
\hline \multirow{2}{*}{ Upper extremity } & Number & 5 & 1 & 6 \\
\cline { 2 - 5 } & Percentage & $3.60 \%$ & $7.10 \%$ & $4.00 \%$ \\
\cline { 2 - 5 } & Number & 19 & 1 & 20 \\
\hline Lower & Number & 31 & $7.10 \%$ & $13.20 \%$ \\
\hline extremity & Percentage & $22.60 \%$ & $28.60 \%$ & 35 \\
\hline
\end{tabular}

Table 4: Breslow thickness in pigmented and amelanotic MM

\begin{tabular}{|l|l|l|l|l|l|l|l|}
\hline $\begin{array}{l}\text { Breslow thickness } \\
\text { Melanoma }\end{array}$ & In situ & $\begin{array}{l}\text { Invasion } \\
\mathbf{< 7 5 m m}\end{array}$ & $\begin{array}{l}\text { Invasion } \\
\mathbf{0 . 7 6 - 1} \mathbf{~ m m}\end{array}$ & $\begin{array}{l}\text { Invasion } \\
\mathbf{1 . 1 - 2} \mathbf{m m}\end{array}$ & $\begin{array}{l}\text { Invasion } \\
\mathbf{2 . 1 - 4 m m}\end{array}$ & $\begin{array}{l}\text { Invasion } \\
\mathbf{>} \mathbf{4} \text {.1mm }\end{array}$ & Total \\
\hline $\begin{array}{l}\text { Pigmented melanoma } \\
\text { (n) }\end{array}$ & 10 & 18 & 9 & 31 & 38 & 31 & 137 \\
\hline $\begin{array}{l}\text { Amelanotic melanoma } \\
\text { (n) }\end{array}$ & 0 & 1 & 1 & 1 & 4 & 7 & 14 \\
\hline Total & 10 & 19 & 10 & 32 & 42 & 38 & 151 \\
\hline
\end{tabular}


Table 5: Distribution of patients with pigmented and amelanotic MM by Clark level of invasion

\begin{tabular}{|c|c|c|c|c|c|c|}
\hline $\begin{array}{l}\text { Clark level of } \\
\text { invasion }\end{array}$ & $(I)^{1}$ & $(I I)^{2}$ & $(I I I)^{3}$ & $(\mathrm{IV})^{4}$ & $(V)^{5}$ & \\
\hline Type of melanoma & Intraepidermal & $\begin{array}{l}\text { Partial invasion } \\
\text { of the papillary } \\
\text { dermis }\end{array}$ & $\begin{array}{l}\text { Fill and/or } \\
\text { expand the } \\
\text { papillary dermis }\end{array}$ & $\begin{array}{l}\text { Invasion of } \\
\text { reticular } \\
\text { dermis }\end{array}$ & $\begin{array}{l}\text { Invading the } \\
\text { subcutaneous } \\
\text { fat or deeper }\end{array}$ & Total \\
\hline $\begin{array}{l}\text { Pigmented } \\
\text { melanoma (n) }\end{array}$ & 15 & 13 & 41 & 58 & 10 & 137 \\
\hline $\begin{array}{l}\text { Amelanotic } \\
\text { melanoma (n) }\end{array}$ & 1 & 1 & 3 & 8 & 1 & 14 \\
\hline Total & 16 & 14 & 44 & 66 & 11 & 151 \\
\hline
\end{tabular}

${ }^{1}$ level I - Intraepidermal

${ }^{2}$ level II - Partial invasion of the papillary dermis

${ }^{3}$ level III - Fill and/or expand the papillary dermis

${ }^{4}$ level IV - Invasion of reticular dermis

${ }^{5}$ level V - Invading the subcutaneous fat or deeper

Table 6: Distribution of patients by TNM stage

\begin{tabular}{|l|l|l|l|l|l|l|l|l|l|}
\hline $\begin{array}{l}\text { Stage } \\
\text { melanoma }\end{array}$ & 0 & Ia & Ib & Ila & IIb & Ilc & III & IV & Total \\
\hline $\begin{array}{l}\text { Pigmented } \\
\text { melanoma (n) }\end{array}$ & 9 & 21 & 25 & 13 & 12 & 17 & 8 & 32 & 137 \\
\hline $\begin{array}{l}\text { Amelanotic } \\
\text { melanoma (n) }\end{array}$ & 0 & 0 & 1 & 0 & 1 & 2 & 4 & 6 & 14 \\
\hline Total $(\mathrm{n})$ & 9 & 21 & 26 & 13 & 13 & 19 & 12 & 38 & 151 \\
\hline
\end{tabular}

Table 8: Distribution of patients by lymph dissection

\begin{tabular}{|l|l|l|l|l|l|}
\hline & $\begin{array}{l}\text { Not } \\
\text { done }\end{array}$ & $\begin{array}{l}\text { Done after } \\
\text { SLBN }\end{array}$ & $\begin{array}{l}\text { Done after } \\
\text { positive } \\
\text { lymph nodes }\end{array}$ & $\begin{array}{l}\text { Done after } \\
\text { SLBN and } \\
\text { positive lymph } \\
\text { nodes }\end{array}$ & Total \\
\hline Pigmented melanoma & 96 & 6 & 34 & 1 & 137 \\
\hline Amelanotic melanoma & 7 & 0 & 7 & 0 & 14 \\
\hline Total & 103 & 6 & 41 & 1 & 151 \\
\hline
\end{tabular}

* Sentinel lymph node biopsy 